\title{
Analysis of Determinants Influencing Students' Academic Achievement in English and Mathematics Subjects of Ending Classes of Schools at Bahir Dar and Debre Tabor Towns, Ethiopia
}

\author{
Endris Assen Ebrahim ${ }^{1}$, Mulugeta Alemayehu Dagnaw ${ }^{2}$ \\ ${ }^{1}$ Department of Statistics, Debre Tabor University, South Gondar, Ethiopia \\ ${ }^{2}$ Department of Mathematics, Debre Tabor University, South Gondar, Ethiopia
}

Email address:

end384@gmail.com (E. A. Ebrahim), assen_endris@yahoo.com (E. A. Ebrahim), malemayehu3@gmail.com (M. A. Dagnaw)

\section{To cite this article:}

Endris Assen Ebrahim, Mulugeta Alemayehu Dagnaw. Analysis of Determinants Influencing Students' Academic Achievement in English and Mathematics Subjects of Ending Classes of Schools at Bahir Dar and Debre Tabor Towns, Ethiopia. International Journal of Secondary Education. Vol. 3, No. 6, 2015, pp. 61-66. doi: 10.11648/j.ijsedu.20150306.12

\begin{abstract}
Quality education is the question of many countries. Students' achievement were a measure of teaching-learning process. Scholars suggested that regardless of the subject nature, many factors affect students' achievements in each school subject. This study is an attempt to determine factors influencing academic achievements of grade 8, 10 and 12 students in Debre Tabor Town (DT) and Bahir Dar Town (BDT) in 2013-2014 academic year with achievements variations occurred in student, class and school levels. Depending on the objectives descriptive analysis and multivariate multilevel linear regression analysis with maximum likelihood estimation were used to analyze the data. The results of BDT data show that school type and average work load of teachers jointly show a significant effect on both subjects; Teachers experience in terms of Mathematics, class size and availability of reference and text books in terms of English show significant influence on academic achievements. From the study, it was found out that multilevel modeling is much better than the single level ordinary regression model in fitting the data and in explaining the variations of the academic achievement at different levels. Likewise, on average non-governmental school students achievements were better than governmental. It can be concluded from this study that the variation of academic achievement of students in each grade level of mathematics and English subjects high within class followed by between schools. It can be recommended that academic facilities and managements at schools and home, and students personal efforts need to be improved in order to achieve better quality of education in all fields of studies at high standard.
\end{abstract}

Keywords: Multivariate Multilevel Analysis, Variation, Academic Achievements, Empty (null) Model

\section{Introduction}

Quality education has been the primary focus of different governments for centuries. The socio-economic development of many countries has been strongly linked with education. Basic education especially helps to reduce poverty through its effects on population growth rate, health, and nutrition and by equipping people to participate in the economy and society. Literacy and numeracy have been central to the Ethiopian school curriculum since permanent free general education was introduced after attaining a democratic government. Regardless of State requirements or curriculum history, the acquisition of adequate literacy and numeracy skills is a vital educational outcome for young people. Such skills have consequences for further study, labor market experiences and, more generally, social wellbeing. Today, there is still much focus on the literacy and numeracy skills of students in Ethiopian schools (Sheldon R. and Julie M., 2003; Anastacia N., 2011).

As Ethiopia has moved toward globalization, students need competence in English in order to communicate in the world market. Thus, English as a long established foreign language used for this purpose have continued to be one of the languages taught. It is also a medium of instruction at primary (second cycle), secondary and tertiary education now a days (UNESCO, 2007). Aziz (1992), from his findings revealed that the respondents agreed to the importance of English Language in everyday life as well as career opportunity. However, they felt that learning Science and Mathematics was very difficult and 
demanding. This is due to the lack of ability in understanding of the subject matters and the instruction language. The result also showed that learning science is more difficult than learning Mathematics due to instruction language.

Moreover, the progress of science and technology is the major area where society comes up for essential means of solving problems, adaptability to the environment and brings civilization by developing the necessary knowledge, ability, skill and attitude. Mathematics education is then the basis of all fields of sciences being it social or natural science. Hence teaching Mathematics at high school level should be given due emphasis towards the development of the society/country. However, studies examined the contribution of each factor on explaining the variance of students' Mathematics achievement and the total variance that could be explained by the determined factors. Mathematics self-concept, home background, teaching learning and students attitude explained $12.3 \%, 5.1 \%, 1.6 \%$ and 0.9 percent of the variance, respectively (Kassahun and Zelalem, 2006).

\section{Methodology}

\subsection{Study Area and Population}

The study covers Debre Tabor Town and Bahir Dar Town, and the study was conducted at Debre Tabor which is the Zonal town of South Gondar, which was established in early in Ethiopian History. The target population for this study was selected schools having either grade 8 , grade 10 and grade 12 students of both government and non-government schools registered in 20013-2014 academic year at Debre Tabor and Bahir Dar Towns. The reason of choosing these grade levels is that the Ethiopian schooling has a standard uniform regional exam for grade 8 students and national exam for grades 10 and 12 students.

\subsection{Data Collection and Sources}

The primary data was collected from the students using a designed questionnaire. The secondary data was taken from the school, educational bearue of the target towns and the zones on some related variables and regional and national exam results of students on Mathematics and English. The regional exam scores was taken for grade 8 students and the national exam scores of grade 10 and 12 result used as achievement measure for students. Then, the exam scores were scaled in to 4.00 point scaling and standardized for both school subjects and all grade students.

\subsection{Sample Size Determination}

Accordingly, the general formula for sample size determination that was adopted for this study is:

$$
n=\frac{\sum_{h=1}^{2} \frac{W_{h}^{2} S_{h}^{2}}{w_{h}}}{V+\frac{1}{N} \sum_{h=1}^{2} W_{h} S_{h}^{2}}
$$

Where $h=$ the stratum; $W_{h}=N_{h} / N=$ stratum weight and $N_{h}=$ number of units in sample $\quad V=\left(\frac{d}{z_{\alpha} / 2}\right)^{2}$ and $S_{h}^{2}=\frac{\sum_{i=1}^{N_{h}}\left(y_{h i}-\overline{Y_{h}}\right)^{2}}{N_{h}-1}$

$\mathrm{S}_{1}^{2}=$ government school sample variance of students' academic performance

$\mathrm{S}_{2}{ }^{2}=$ non-government school sample variance of students' academic performance

$\bar{y}_{1}=$ government school students sample mean of students' academic performance

$\bar{y}_{2}=$ non-government school students sample mean of students' academic performance

There are four methods of estimating $s^{2}$ for calculating sample size of the study. These are by taking the sample in two steps, by the results of a pilot survey and by previous sampling of the same or similar population and guesswork about the structure of the population (Cochran, 1977).

At DTT 9 schools were taken, such that $N=N_{1}+N_{2}=$ $1,714+8,050=9,764$ is total population size at both school types of DTT. In this study the proportional allocation: $w_{h}=$ $W_{h}=N_{h} / N$ is more convenient for computing the sample size $n$.

$$
\begin{gathered}
n_{0}=\frac{\sum_{h=1}^{2} W_{h} S_{h}^{2}}{V}=\left(\frac{z_{\alpha} / 2}{d}\right)^{2} \sum_{h=1}^{2} W_{h} S_{h}^{2}= \\
\left(\frac{1.96}{0.04}\right)^{2}\left(\frac{1714 \times 0.3}{9764}+\frac{8050 \times 0.13}{9764}\right)=420 \\
n=\frac{n_{0}}{1+\frac{n_{0}}{N}}=\frac{420}{1+\frac{420}{9764}}=402
\end{gathered}
$$

(Total sample size for both private and governmental schools at DTT).

In a similar manner, for BDT of all 38 schools 13 schools were selected randomly which have a population size $\mathrm{N}=8050$, of which the population size for the selected 4 private schools $\mathrm{N}_{1}=1189$, and the population size for the selected 9 governmental schools was $\mathrm{N}_{2}=6861$ then the sample size is calculated as:

$$
\begin{gathered}
n_{0}=\frac{\sum_{h=1}^{2} W_{h} S_{h}^{2}}{V}=\left(\frac{z_{\alpha} / 2}{d}\right)^{2} \sum_{h=1}^{2} W_{h} S_{h}^{2}= \\
\left(\frac{1.96}{0.04}\right)^{2}\left(\frac{1189 \times 0.3}{8050}+\frac{6861 \times 0.13}{8050}\right)=455 \\
n=\frac{n_{0}}{1+\frac{n_{0}}{N}}=\frac{455}{1+\frac{455}{8050}}=431
\end{gathered}
$$


(Sample size for both private and governmental schools at BDT).

In general, a total of 833 students were considered in the study for the two targeted towns.

\subsection{Specification of Statistical Models}

A multilevel linear regression model is a formalized statistical expression enabling the study of simultaneous effects of factors from students, classes (teachers) and school, highest level on academic achievement of students. The Univariate and Multivariate models were built using four-levels of hierarchy: school subjects within students within class (teachers) within school, which involves different steps for estimation: null and final models (random intercept and random slope models). The null model involves no predictors or explanatory variables are specified at any level. The final model (random intercept or random slope model) involves random intercept and explanatory variables from any levels (student level, class level and school level). The Univarite /Multivariate/ distinction refers to whether the model fit uses a single subject matter test for each student or both subject matter tests (Math and Eng).

The Empty (Null) Model

$$
Y_{i j k l}=\beta_{0}+f_{0 l}+\nu_{0 k l}+v_{o j k l}+e_{o i j k l}
$$

Where, $i$ denotes subject matter test, indicating math/Eng/, $j$ denotes student, $k$ denotes class (teacher), and $l$ denotes school. $f_{0 l}, \nu_{0 k l}, v_{o j k l}, e_{o i j k l}$ are the level 4(school), level 3(class/teacher), level 2(student) and level 1(subject matter) residuals, respectively, and $\operatorname{var}\left(f_{0 l}\right)=\sigma_{f 0}^{2}, \operatorname{var}\left(\nu_{0 k l}\right)=\sigma_{\nu 0}^{2}$, $\operatorname{var}\left(v_{0 j k l}\right)=\sigma_{v 0}^{2}$, and $\operatorname{var}\left(e_{0 i j k l}\right)=\sigma_{e 0}^{2} \cdot \beta_{0}$ is interpreted as the overall average of academic achievement and $Y_{i j k l}$ is academic achievement in the $i^{\text {th }}$ subject for $j^{\text {th }}$ student of $k^{\text {th }}$ class (teacher) of $l^{\text {th }}$ school.

The null model is used for different purposes:

1. To decompose the total variance.

2. To estimate the interclass correlation

3. To measure how much of the variation is explained by the model with no predicators included. The total variance is decomposed as the sum of the school-level, class level, student level, and subject matter level variances:

$$
\begin{gathered}
\operatorname{var}\left(Y_{i j k l}\right)=\operatorname{var}\left(f_{0 l}\right)+\operatorname{var}\left(\nu_{0 k l}\right)+\operatorname{var}\left(v_{0 j k l}\right)+\operatorname{var}\left(e_{0 i j k l}\right) \\
=\sigma_{f 0}^{2}+\sigma_{\nu 0}^{2}+\sigma_{v 0}^{2}+\sigma_{e 0}^{2}
\end{gathered}
$$

The variances $\sigma_{f}^{2}, \sigma_{\nu}^{2}, \sigma_{v}^{2}$ and $\sigma_{e}^{2}$ estimate the variation among schools within the DTT, among classes (teachers) within school, among students within classes (teachers) and between subject matters among students, respectively. It is, therefore, possible to decompose the variance at two levels to assess how much of the variation is due to students themselves and how much is due to school. The interclass correlation (ICC) is given as follows: $I C C=\rho=\frac{\sigma_{f}^{2}}{\sigma_{e}^{2}+\sigma_{f}^{2}}=\frac{\sigma_{f}^{2}}{\sigma_{Y}^{2}}$ This measure the correlation between variables on the same levels or proportion of group (school/ class) level variance compared to total variance. It can also be interpreted as the expected correlation between two randomly chosen units in the same level and to check within and between variations of colleges on academic achievement of students. Next, predicators of any levels are added to the null model to obtain the final model known as random intercept and fixed explanatory model (Goldstein, 2010).

The Final Model

$$
\begin{aligned}
& Y_{i j k l}=\underbrace{\beta_{o}}_{\begin{array}{c}
\text { overall } \\
\text { mean }
\end{array}}+\underbrace{\beta_{1} X_{1 i j}+\ldots+\beta_{m} X_{m i j}+e_{i j k l}+v_{i j k}}_{\text {Student and Subject Matter Level }}+\underbrace{\beta_{m+1} X_{m+1 k l}+\ldots+\beta_{n} X_{k l}+f_{l}+\nu_{k l}}_{\text {Class and School Level }} \\
& Y_{i j k l}=\underbrace{\beta_{o}}_{\begin{array}{c}
\text { overall } \\
\text { mean }
\end{array}}+\underbrace{\beta_{1} X_{1 i j}+\ldots+\beta_{m} X_{m i j}+e_{i j k l}+v_{i j k}}_{\text {Student and Subject Matter Level }}+\underbrace{\beta_{m+1} X_{m+1 j} f_{l}+\ldots+\beta_{n} X_{n j} f_{l}+f_{l}+\nu_{k l}}_{\text {Class and School Level }}
\end{aligned}
$$

Where

Equation 1: is called random intercept model, a model having all explanatory variables.

Equation 2: is called random slope model, a model having all explanatory variables but some variables vary at any level, usually at the highest level.

$e_{i j k l}$ is level one variance, $v_{j k l}$ is level two variance, $\nu_{k l}$ is

level three variance, $f_{l}$ is level four variance, $m$ student with subject matter-level explanatory variables and $n-m$ school with class(teacher)-level explanatory variables.

\section{Results and Discussions}

\subsection{Descriptive Statistics}

From the results of DTT schools indicated in Table 1 below, the average (mean) scores of sampled students at governmental schools of grade 8 were 2.72 in mathematics and 2.85 in English. Gafate primary school has covered the first rank in the sample with mean scores 3.22 in mathematics and 2.94 in English. For sampled grade 10 governmental schools, the mean scores were 3.11 in mathematics and 2.74 in English. Tewodros II secondary school has the first rank with mean scores 3.67 in mathematics and 3.48 in English. The only grade 12 
preparatory school, Tewodros II secondary and preparatory, has mean scores 3.28 in mathematics and 2.64 in English. Moreover, the average (mean) scores for sample non-governmental schools of grade 8 were 3.31 in mathematics and 2.85 in English. DT academy has the first rank in average scores of both subjects that scores 3.55 in mathematics and 2.95 in English. From the sample schools total average result non-governmental schools are better in mathematics achievement than government. However there was no more average difference in English between school types.

Table 1. Cross Tabulation of School Type and Each School Vs the Mean and Standard deviation of Students Achievement in Each Selected Subject (Debre Tabor, 2013/2014).

\begin{tabular}{|c|c|c|c|c|c|}
\hline $\begin{array}{l}\text { School } \\
\text { type }\end{array}$ & $\begin{array}{l}\text { Grade } \\
\text { level }\end{array}$ & Name of the $s$ & ool & Maths & English \\
\hline \multirow{12}{*}{$\begin{array}{l}\text { Govern } \\
\text { mental }\end{array}$} & \multirow{12}{*}{$\begin{array}{l}\text { Grade } \\
8\end{array}$} & \multirow{3}{*}{ Gafat } & $\mathrm{N}$ & 32 & 32 \\
\hline & & & Mean & 3.22 & 2.94 \\
\hline & & & Std. D & 0.75 & 0.76 \\
\hline & & \multirow{3}{*}{$\begin{array}{l}\text { Tewodros II } \\
\text { primary }\end{array}$} & $\mathrm{N}$ & 23 & 23 \\
\hline & & & Mean & 2.74 & 2.78 \\
\hline & & & Std. D & 0.61919 & 0.90235 \\
\hline & & \multirow{3}{*}{$\begin{array}{l}\text { Fitawurarigeb } \\
\text { riye }\end{array}$} & $\mathrm{N}$ & 28 & 28 \\
\hline & & & Mean & 2.14 & 2.82 \\
\hline & & & Std. D & 0.76 & 0.72 \\
\hline & & \multirow{3}{*}{ Total } & $\mathrm{N}$ & 83 & 83 \\
\hline & & & Mean & 2.72 & 2.86 \\
\hline & & & Std. D & 0.85 & 0.78 \\
\hline \multirow{18}{*}{$\begin{array}{l}\text { Govern } \\
\text { mental }\end{array}$} & \multirow{15}{*}{$\begin{array}{l}\text { Grade } \\
10\end{array}$} & \multirow{3}{*}{$\begin{array}{l}\text { Debre Tabor } \\
\text { General Sec. }\end{array}$} & $\mathrm{N}$ & 46 & 46 \\
\hline & & & Mean & 3.24 & 2.68 \\
\hline & & & Std. D & 0.71 & 0.79 \\
\hline & & \multirow{3}{*}{$\begin{array}{l}\text { Tewodros II } \\
\text { second. and } \\
\text { preparatory }\end{array}$} & $\mathrm{N}$ & 27 & 27 \\
\hline & & & Mean & 3.67 & 3.48 \\
\hline & & & Std. D & 0.48 & 0.58 \\
\hline & & \multirow{3}{*}{ Ferte } & $\mathrm{N}$ & 48 & 48 \\
\hline & & & Mean & 3.08 & 2.52 \\
\hline & & & Std. D & 0.77 & 0.77 \\
\hline & & \multirow{3}{*}{ Tayitu } & $\mathrm{N}$ & 23 & 23 \\
\hline & & & Mean & 2.30 & 2.48 \\
\hline & & & $\begin{array}{l}\text { Std. } \\
\text { Deviation }\end{array}$ & 0.63495 & 0.59311 \\
\hline & & \multirow{3}{*}{ Total } & $\mathrm{N}$ & 144 & 144 \\
\hline & & & Mean & 3.11 & 2.74 \\
\hline & & & Std.D & 0.79 & 0.79 \\
\hline & \multirow{3}{*}{$\begin{array}{l}\text { Grade } \\
12\end{array}$} & \multirow{3}{*}{$\begin{array}{l}\text { Tewodros II } \\
\text { second. and } \\
\text { preparatory }\end{array}$} & $\mathrm{N}$ & 104 & 104 \\
\hline & & & Mean & 3.28 & 2.64 \\
\hline & & & Std. D & 0.61 & 0.77 \\
\hline \multirow{9}{*}{$\begin{array}{l}\text { None-G } \\
\text { overnm } \\
\text { ental }\end{array}$} & \multirow{9}{*}{$\begin{array}{l}\text { Grade } \\
8\end{array}$} & \multirow{3}{*}{$\begin{array}{l}\text { Dalsha } \\
\text { Bezawit Alem }\end{array}$} & $\mathrm{N}$ & 29 & 29 \\
\hline & & & Mean & 2.96 & 2.68 \\
\hline & & & Std. D & 0.62 & 0.60 \\
\hline & & \multirow{3}{*}{ DT academy } & $\mathrm{N}$ & 42 & 42 \\
\hline & & & Mean & 3.55 & 2.95 \\
\hline & & & Std. D & 0.59 & 0.91 \\
\hline & & \multirow{3}{*}{ Total } & $\mathrm{N}$ & 71 & 71 \\
\hline & & & Mean & 3.31 & 2.85 \\
\hline & & & Std. D & 0.67 & 0.80 \\
\hline
\end{tabular}

From the results of BDT schools indicated in in a similar way, the average (mean) scores of students in the sample grade 8 governmental schools were 2.58 in mathematics and 2.63 in
English. For sample grade 12 students of the selected governmental schools, the average (mean) scores were 2.56 in mathematics and 2.54 in English. The average (mean) scores in mathematics and English for non-governmental schools at BDT were 2.83 and 2.75 in grade 8, 3.05 and 3.29 in grade 10, respectively.

From the descriptive analyses, students strongly agree on most of the items in DTT. Relatively, the same rates of percentages were observed on most of the items in both mathematics and English subjects at DTT and BDT. The rates showed that almost there is no peer work/ team working/ among students, and students strongly agreed that lots of hard working is needed to achieve better in mathematics and English subjects. Moreover, the students' ratings on school facilities and inputs showed that most of the inputs and facilities are available in high or medium levels of percentage. However, no health services (first aids) and laboratory facilities and equipment in schools at both DTT and BDT.

\subsection{Multilevel Multivariate Multiple Linear Regression Analyses Results}

\section{MVML Random Intercept Model Analysis}

The fixed part of Table 2 below, shows that age, basic needs and average work load of teachers' jointly statistically significant explanatory variables on both achievement measures of the two school subjects at DTT. School type, sex, class size and parent to teacher communication are statistically significant on achievement of students in terms Mathematics at DTT. Moreover, students' food satisfaction at home and students to teacher ratio are statistically significant in terms of English subject at DTT. On the other hand, the result showed that, on average, the academic achievements of female students were better than male students in mathematics at grade eight, ten and twelve. Likewise, on average students learning at governmental secondary schools achieve worse in Mathematics subject as compared to the students learning at non-governmental schools of grade 8, 10 and 12 .

The random part of the model (Table 2) also shows that both the school subjects have larger variances at student level than school and class levels. There are no achievement variations at class level on both subjects. The largest achievement variations were observed in mathematics due to school effects (level-4), and in English due to student effects (level-2). There are statistically significant achievement variations in both subjects at school level (level-4) and student level. The covariance of the two subjects at the students' level is negative .however the covariance of Maths and English at school level is weak positive. This implies that, even though, schools show some association of effect/ correlation/ in the two subjects, but the students were not correlated the two subjects in practice.

The shown in Table 3 below, shows that school type and average work load of teacher's jointly statistically significant explanatory variables on both achievement measures of the two school subjects at BDT. Teacher experience is statistically significant on achievement of students in terms Mathematics at BDT. Moreover, class size and availability of text and 
reference books at home are statistically significant in terms of English subject at BDT. On the other hand, the result showed that, on average, students learning at governmental secondary schools achieve worse in both Mathematics and English subjects as compared to the students learning at non-governmental schools of grade 8, 10 and 12 .

Table 2. Parameter Estimates of Multivariate Multilevel Regression and Fixed Slope Model (DTT, 2013/2014).

\begin{tabular}{|c|c|c|c|c|c|c|c|}
\hline \multicolumn{8}{|l|}{ Fixed Parts } \\
\hline \multirow{2}{*}{$\begin{array}{l}\text { Dependent / } \\
\text { response / Variable }\end{array}$} & \multirow{2}{*}{$\begin{array}{l}\text { Parameter } \\
\text { (covariates) }\end{array}$} & \multirow{2}{*}{ Estimate (B) } & \multirow{2}{*}{ Std. Error } & \multirow{2}{*}{$\mathbf{t}$} & \multirow{2}{*}{ Sig. (p-value) } & \multicolumn{2}{|l|}{$95 \% \mathrm{CI}$} \\
\hline & & & & & & Lower Bound & Upper Bound \\
\hline \multirow{11}{*}{ Mathematics } & Intercept & .299 & .528 & .566 & .572 & -.740 & 1.338 \\
\hline & $\operatorname{Sex}(\mathrm{M})$ ref.F & -.165 & .082 & -2.004 & $.046 *$ & -.326 & -.003 \\
\hline & Age & .055 & .025 & 2.184 & $.030 *$ & .006 & .105 \\
\hline & SchoolType(NG) & .546 & .128 & 4.275 & $.000 *$ & .295 & .797 \\
\hline & Class Size & .014 & .006 & 2.438 & $.015^{*}$ & .003 & .025 \\
\hline & FoodSatifacHome & .016 & .036 & .455 & .650 & -.054 & .086 \\
\hline & Ref. Books & -.029 & .039 & -.741 & .459 & -.105 & .048 \\
\hline & EducTools & .026 & .035 & .761 & .447 & -.042 & .094 \\
\hline & BasicNeeds & .073 & .035 & 2.086 & $.038 *$ & .004 & .142 \\
\hline & AvWorkLoad & -.132 & .062 & -2.129 & $.034 *$ & -.254 & -.010 \\
\hline & StuTeaRatio & .126 & .061 & 2.056 & $.040 *$ & .005 & .246 \\
\hline \multirow{10}{*}{ English } & Intercept & 3.662 & .546 & 6.707 & .000 & 2.588 & 4.736 \\
\hline & SchoolType(NG) & -.070 & .132 & -.532 & .595 & -.330 & .189 \\
\hline & Class Size & .001 & .006 & .100 & .920 & -.011 & .012 \\
\hline & PartTecherComunic & .090 & .052 & 1.724 & .086 & -.013 & .193 \\
\hline & FoodSatifacHome & -.075 & .037 & -2.025 & $.044 *$ & -.147 & -.002 \\
\hline & Ref. Books & -.012 & .040 & -.294 & .769 & -.091 & .067 \\
\hline & EducTools & .034 & .036 & .944 & .346 & -.037 & .104 \\
\hline & BasicNeeds & .082 & .036 & 2.269 & $.024 *$ & .011 & .154 \\
\hline & AvWorkLoad & -.133 & .064 & -2.078 & $.038 *$ & -.259 & -.007 \\
\hline & StuTeaRatio & .134 & .063 & 2.122 & $.035 *$ & .010 & .259 \\
\hline
\end{tabular}

*Significant $(\mathrm{P}$-value $<0.05)$; the $\mathrm{CI}$ does not contain the value zero.

Table 3. Parameter Estimates of Multivariate Multilevel Regression and Fixed Slope Model (Bahir Dar, 2013/2014).

\begin{tabular}{|c|c|c|c|c|c|c|c|}
\hline \multicolumn{8}{|l|}{ Fixed parts } \\
\hline \multirow{2}{*}{$\begin{array}{l}\text { Dependent /Response / } \\
\text { Variable }\end{array}$} & \multirow{2}{*}{$\begin{array}{l}\text { Parameter } \\
\text { (covariates) }\end{array}$} & \multirow{2}{*}{ Estimate (B) } & \multirow{2}{*}{ Std. Error } & \multirow{2}{*}{$\mathbf{t}$} & \multirow{2}{*}{ Sig. (p-value) } & \multicolumn{2}{|l|}{$95 \%$ CI } \\
\hline & & & & & & Lower Bound & Upper Bound \\
\hline \multirow{12}{*}{ Mathematics } & Intercept & 1.609 & 1.008 & 1.597 & .111 & -.373 & 3.591 \\
\hline & $\operatorname{Sex}(M)$ & .076 & .119 & .641 & .522 & -.158 & .311 \\
\hline & Age & .022 & .031 & .686 & .493 & -.040 & .083 \\
\hline & Class Size & -.011 & .008 & -1.294 & .197 & -.027 & .006 \\
\hline & School Type(NG) & .392 & .193 & 2.033 & $.043 *$ & .013 & .771 \\
\hline & Basic Needs & -.050 & .054 & -.919 & .359 & -.156 & .057 \\
\hline & Avworkload & .229 & .112 & 2.047 & $.041 *$ & .009 & .450 \\
\hline & TeachExp & .179 & .084 & 2.122 & $.035^{*}$ & .013 & .345 \\
\hline & HomeTextRefrence & -.062 & .063 & -.984 & .326 & -.185 & .062 \\
\hline & SchEnvirntComf & .067 & .062 & 1.083 & .280 & -.055 & .189 \\
\hline & FoodSatifacHome & .064 & .056 & 1.139 & .256 & -.046 & .174 \\
\hline & EducTools & -.041 & .050 & -.816 & .415 & -.140 & .058 \\
\hline \multirow{12}{*}{ English } & Intercept & 2.017 & .929 & 2.170 & .031 & .189 & 3.845 \\
\hline & $\operatorname{Sex}(M)$ & .127 & .110 & 1.156 & .249 & -.089 & .344 \\
\hline & Age & .026 & .029 & .890 & .374 & -.031 & .083 \\
\hline & ClassSize & -.016 & .008 & -2.015 & $.045^{*}$ & -.031 & .000 \\
\hline & SchoolType(NG) & .369 & .178 & 2.073 & $.039 *$ & .019 & .718 \\
\hline & BasicNeeds & -.077 & .050 & -1.535 & .126 & -.175 & .022 \\
\hline & Avworkload & .244 & .103 & 2.360 & $.019^{*}$ & .041 & .447 \\
\hline & TeachExp & .044 & .078 & .566 & .572 & -.109 & .197 \\
\hline & HomeTextRefrence & .116 & .058 & 2.011 & $.045 *$ & .003 & .230 \\
\hline & SchEnvirntComf & .078 & .057 & 1.367 & .172 & -.034 & .191 \\
\hline & FoodSatifacHome & .000 & .052 & -.011 & .991 & -.102 & .101 \\
\hline & EducTools & -.015 & .047 & -.317 & .751 & -.106 & .077 \\
\hline
\end{tabular}

*Significant $(\mathrm{P}$-value $<0.05)$ : the CI does not contain the value zero. 


\section{Conclusions}

The study showed that non-governmental school students of different grade levels performed better than governmental schools in both subjects at both towns. Higher school and student level variations were observed in DTT than BDT. Female students perform better than male students in mathematics at DTT. From the multilevel multivariate regression analyses of the fixed parts and random parts the following inferences are observed:

The factors or student level characteristics like age, sex, availability of reference and text books at home, food satisfaction of students at home and parent-teacher communication are significant factors affecting students' achievement in Maths and English of grade 8, 10 and 12.

The class level factors or characteristics like class size, teacher experience, average work load of teachers, studentteacher-teacher ratio are significant factors affecting students' achievement in Maths and English of grade 8, 10 and 12.

The factors or school level characteristics like school type and basic needs are the significant factors affecting students' achievement in Maths and English of grade 8, 10 and 12.

\section{Recommendations}

As there are variations of academic achievements of students at school and student levels of DTT, it is recommended to adjust the home-student and school-teacher characteristics. The schools should attention to improve the insufficient school facilities such as human resources, library facilities, laboratory facilities, school amenities and academic counseling and supportive services to slowdown the achievement variation between government and non-government schools. Besides, to minimize the achievement variations among students within class, appropriate intervention can be done in evenly distributing resources and facilities required at home for students and parents' involvement to refresh students from educational tension and parents should be inspect the students' perception and attitude about lessons, especially government school students.

\section{List of Abbreviations}

BDT $=$ Bahir Dar Town

$\mathrm{CI}=$ Confidence Interval

DTT $=$ Debre Tabor Town

Eng $=$ English as a school subjects

IGLS = Iterative Generalized Least Squares

LANNA $=$ Literacy and Numeracy National Assessment

Math $=$ Mathematics as a school subject
MLwiN $=$ Multilevel Window

MVML $=$ Multivariate Multilevel

MVN = Multivariate Normal

UNESCO $=$ United Nations Educational Scientific and

Cultural Organization

$\mathrm{WDE}=$ World Data on Education

\section{References}

[1] Anastacia, N. (20011). Factors Affecting the National Achievement Test Performance Of Selected Second Year High School Students, In Santa Maria, Bulacan.

[2] Aziz, N. (1992). Students' Perception on Teaching and Learning Mathematics in English, Faculty of Education, Universiti Teknologi Malaysia.

[3] Cochran, W.G. (1997). Sampling Techniques, (3 ${ }^{\text {rd }}$ ed.), John Wiley and Sons, New York.

[4] Engin-Demir, C. (2009). Factors Affecting the Academic Achievement of Turkish Urban Poor, International Journal of Educational Development, 29.

[5] Goldstein, H. (2010). Multilevel Statistical Models (4th Ed.), Wiley Series in Probability and Statistics, University of Bristol, UK, John Wiley and Sons, Ltd., Publication.

[6] Kassahun, M. and Zelalem, T. (2006). Assessment on the Impact of Plasma Television Implementation on the Teaching Learning Process of Mathematics Class: The Case on Selected High Schools, Mathematics Department, Education Faculty, Jimma University, Jimma, Ethiopia.

[7] Sheldon R. And Julie, M. (2003). Longitudinal Survey of Australian Youth, research report36, Influences on Achievement in Literacy and Numeracy, Australian Council for Educational research.

[8] Marilyn G., and Janine G. (2004). Leading Math Success: From the Chairs of the Expert Panels on Student Success in Ontario: Mathematical Literacy, Grades 7-12, The Report of the Expert Panel on Student Success in Ontario.

[9] Snijders, T. and Bosker, J. (1999). Multilevel Data and Multilevel Analysis: An Introduction to Basic and Advanced Multilevel Modeling, SAGE Publications, Thousand Oaks New Delhi, London.

[10] Tadesse, S. (2009). Understanding Female Students' Academic Performance: An Exploration of the Situation in South Nations Nationalities and Peoples Regional State, Ethiopia, International Institute of Social Studies, The Hague and the Netherlands.

[11] UNESCO-WDE. (2007). World Data on Education (6 ed.), Ethiopia.

[12] Yeshimebrat M., et'al (2013) .Affecting Female Students' Academic Achievement at Bahir Dar University CICE Hiroshima University, Ethiopia, Journal of International Cooperation in Education, Vol.15 No.3. 